\title{
Novos cenários comunicacionais no contexto das mídias interativas: o espalhamento midiático
}

\author{
New communication scenarios in the context of interactive media: the \\ spreadable media
}

\section{Edson Fernando Dalmonte}

Doutor em Comunicação, professor de Comunicação e Ética e do Programa de Pós-Graduação em Comunicação e Cultura Contemporâneas, Faculdade de Comunicação, Universidade Federal da Bahia. Coordenador do Analítica: Crítica de Mídia, Estética e Produtos Midiáticos. <edsondalmonte@gmail.com>

\section{RESUMO}

A partir da realidade atual dos meios de comunicação, tem-se por objetivo verificar as possibilidades de participação do indivíduo nos processos de discussão e visibilidade social. No contexto da recirculação da informação via redes sociais, são feitas considerações acerca dos níveis de participação do leitor/receptor na construção e veiculação da informação. De maneira específica, discutem-se os níveis de interação entre produtos televisivos da TV convencional e sites de redes sociais, com os seguintes objetivos: a) questionar padrões síncronos e assíncronos de audiência; b) verificar indicativos de fortalecimento da audiência e c) verificar distintos usos afastados dos protocolos sugeridos pela instância de produção. A pesquisa evidencia um forte indicativo para o engajamento midiático via redes de conversação, estabelecidos entre consumidores de programação televisiva.

\begin{abstract}
Within the current reality of mass media, there exists an objective to verify the possibilities of individual participation in discussions and his/her social visibility. In the context of the recirculation of information via social networks, considerations about the levels of participation of the reader/ receiver in the construction and broadcast of information were made. In a specific way, the interaction between levels of television products of conventionalTV and social networking sites were discussed here, with the following objectives: a) to question synchronous and asynchronous audience patterns b) to verify indicatives of strengthening the audience, and c) to verify distinct uses distant from suggested protocols by production limits. The survey shows a strong indication to the media engagement via chat networks established between television programming consumers.
\end{abstract}

Keywords: Social networks. Interaction. Recirculation.

\section{Mídia e interação social}

A mídia vem cada vez mais ocupando espaço na vida das pessoas. Sob o ponto de vista da circulação da informação, temos acompanhado a evolução de novos ambientes midiáticos/informacionais que tanto propiciam a maior circulação 
de conteúdos, quanto permitem que os indivíduos participem dos processos de elaboração e distribuição de conteúdos.

De acordo com o quadro evolutivo dos meios de comunicação, temos três fases de consumo midiático:

a) Consumo partilhado: o consumo de produtos radiofônicos e televisivos era feito em grupos, caracterizado pela troca imediata de impressões acerca da programação;

b) Consumo individualizado: com o barateamento dos aparelhos receptores, o consumo é feito de forma privada e, na maioria das vezes, individualmente;

c) Consumo privado e compartilhado: a partir de uma vasta programação disponível, o consumo se dá de forma privada, mas é caracterizado pelo imediato compartilhamento de impressões, explicitadas por meio de sites de redes sociais.

Pode-se dizer que na terceira fase recupera-se o sentido comunitário de ver junto e a estrutura de conversação é ampliada, pois o indivíduo se conecta a um grupo preciso de consumidores, motivado por traços de interesses comuns. Decorrente do cruzamento entre plataformas midiáticas, ou crossmedia (Giovagnoli, 2009; Jenkins, 2008; Jenkins, Ford e Green, 2013), chega-se às audiências cruzadas, configurando novas formas de consumo midiático. Um mesmo produto televisivo, por exemplo, passa a ser apropriado de distintos modos, integrando-se a novas rotinas propostas por sites de redes sociais, como Facebook e Twitter.

Como resultado de tais cruzamentos, podemos afirmar que há novas formas de contato entre as instâncias de Produção e Consumo. À instância de produção, historicamente detentora dos meios de produção e circulação dos produtos comunicacionais, somam-se agora os novos modos de consumo, fortemente caracterizados pela recirculação e reverberação.

Dentre as principais inovações, podemos notar:

a) Rompe-se com a temporalidade do consumo. Antes: os meios controlavam as emissões/publicações, e o consumo deveria obedecer ao tempo proposto pela lógica da circulação (Damonte, 2009a e 2010; Franciscato, 2005). O consumo era síncrono, implicando uma temporalidade compartilhada entre a circulação e a apropriação. Agora: praticamente todo o material circula pelas 
plataformas digitais e o horário de "exibição" ainda importa, mas numa escala menor, pois o consumo passa a ser também assíncrono.

Interessa, dessa forma, perceber a tessitura de novas textualidades, como a propiciada pelos recursos interativos, a exemplo do Twitter e Facebook, que permitem ao usuário comentar um produto e promover a sua recirculação.

b) $\mathbf{O}$ consumidor promove a divulgação de produtos midiáticos. $A$ esfera do consumo passa também a importante elemento para a promoção dos produtos midiáticos contemporâneos, bastando observarmos a importância atribuída aos dispositivos "curtir" e "compartilhar" etc.

c) As lógicas do espalhamento midiático interferem na produção. Cada vez mais os produtos são idealizados para essa nova forma "barulhenta" de consumir, pois interessa que sejam consumidos em vários níveis - síncrona e assincronamente. Como ressaltam Jenkins, Ford e Green (2013), os produtos midiáticos passam a ser concebidos segundo a lógica do "espalhamento" midiático'.

Em detrimento da lógica de circulação midiática tradicional, Jenkins, Ford e Green (2013, p.1) apresentam uma nova ideia, na qual a tal "mídia espalhável" denota a emergência de um modelo híbrido, que explicita a confluência de forças "de cima para baixo" (fluxo convencional) e "de baixo para cima" (novos fluxos participativos decorrentes de redes sociais, por exemplo).

Essa necessária e inevitável mistura de fluxos "alternativos" e "comerciais" torna evidente, assim, uma nova paisagem midiática, na qual os conteúdos são produzidos para uma ampla circulação, compreendendo uma variedade de processos de recirculação. Sobre o novo produto midiático, como pontuam Jenkins, Ford e Green (2013, p.1) de maneira bastante objetiva: "se não se espalhar, está morto"2.

Os produtos midiáticos passam a convocar novas audiências interativas, que consomem de formas variadas e produzem distintos percursos a partir das formas de consumo. Na perspectiva do discurso, ou materialização dos sentidos, todas as partes (dispersas) constituem essa textualidade paratextual. Importa, atualmente, pensar nessa audiência de segunda natureza, integrando públicos e produtos numa temporalidade estendida. Em pesquisa recente, divulgada no dia 06 de agosto de 2013, a Nielsen ${ }^{3}$ aponta clara influência entre os usuários do

No original, Spreadable Media. Spread tem o sentido de espalhar.

2 "If it doesn't spread, it's dead".

$3<$ http://br.nielsen.com/site/index.shtml>. 
Twitter e a audiência de programas televisivos ${ }^{4}$. Realizada com 221 transmissões em horário nobre e comentadas no Twitter, a pesquisa indica que as atrações analisadas fazem aumentar as atividades na rede social durante o tempo de exibição. Por outro lado, a ação via Twitter eleva a pontuação das emissoras na audiência.

Inúmeros acontecimentos recentes nos colocam diante de uma nova realidade: a mobilização social via meios interativos da comunicação. A partir de dispositivos móveis como celulares e tablets, os indivíduos agora participam dos fluxos comunicacionais, tradicionalmente restritos ao âmbito empresarial, detentor dos modos de organização e circulação discursivos. Segundo Badiou (2007, p.97), dentre as características que definem o século XX, está o desejo pelo imediato, que o autor chama de paixão pelo real, "por aquilo que é imediatamente praticável, aqui e agora".

Para além do desejo pelo imediato, configurador do real, Agamben (2012, p.109) indica que toda cultura se estabelece numa determinada experiência do tempo e, da mesma forma, "uma nova cultura não é possível sem uma transformação desta experiência". Podemos dizer que uma nova experiência temporal surge a partir da atual realidade dos meios de comunicação, que nos colocam numa mesma esfera temporal: divulgação dos produtos, consumo e possibilidade de crítica, que passa a se integrar ao produto midiático, sendo esta uma importante característica do contemporâneo.

\section{Nem uma nem outra lógica, mas várias}

A integração entre conteúdo televisivo e internet tem gerado interesse de estudiosos de televisão e tecnologia (Schatz e outros., 2010; Harboe, 2010; Montpetit e outros., 2010; Proulx \& Shepatin, 2012; Ortiz, 2013) ${ }^{5}$. As pesquisas giram em torno do que tem se denominado "Social TV", definida por Schatze outros. (2010, p.257) como "uma tecnologia que permite o compartilhamento da experiência televisiva com o objetivo de promover o uso social da televisão e a interação entre os telespectadores". Assim, a televisão é vista como uma

4 Estudo revela que Twitter influencia diretamente audiência na TV. Pesquisa da Nielsen confirma discurso do microblog em ser uma ponte entre os internautas e a TV. Disponível: < http://www.proxxima. com.br>. Acesso em 11 de agosto de 2013.

5 Para um panorama acerca do tema, consultar: ORTIZ, Júnia. Configurações da experiência televisiva: o consumo social na Internet. Dissertação (Mestrado em Comunicação) Programa de Pós-Graduação em Comunicação. FACOM/UFBA, 2013. <http://www.poscom.ufba.br/publicacoes/ dissertacoes-2006-2013/>. 
experiência social capaz de fortalecer vínculos e laços (Harboe, 2010). De acordo com Schatz e outros. (2010, p.257), a sociabilidade mediada serve como um catalisador para a interação entre os telespectadores, que pode ser classificada de duas formas:

a) sociabilidade direta: a TV como fornecedor de contexto e acontece quando a interação é paralela à exibição de um programa.

b) sociabilidade indireta: interação social que acontece antes e/ou depois do evento em questão e pode ser mobilizada por ferramentas como fóruns de discussão online.

Proulx \& Shepatin (2012, p.10-11) enfatizam o papel daquilo que se nomeia "backchannel"6, algo como um "canal por trás do canal", que se estabelece por meio de milhares de interações em tempo real a partir de produtos televisivos. Essa conversação em rede conecta a experiência televisiva individual e permite a partilha dessa experiência numa escala planetária. A conversação online sobre produtos midiáticos acontece tanto antes, como durante e mesmo após a transmissão de episódios de produtos televisivos, por exemplo.

Contudo, para Proulx \& Shepatin (2012, p.11), o backchannel televisivo é definido a partir da conversação em tempo real durante a transmissão do episódio de um produto televisivo. Essa estrutura de conversação passa à categoria de subtexto que conecta o indivíduo a um grande grupo virtual. $\mathrm{O}$ Twitter é uma das principais redes sociais nesse novo cenário midiático. Dentre os exemplos destacados por Proulx \& Shepatin (2012), está o anúncio feito pela cantora Beyoncé que estava grávida, ocorrido ao final de sua apresentação na premiação norte-americana da MTVVMA (Video Music Awards), em 28 de agosto de $2011^{7}$.

Imediatamente após o anúncio feito pela cantora, foram registrados, em média, 8868 tweets por segundo, proporcionando um rápido espalhamento da notícia em escala global/planetária. Segundo os autores, o Twitter propicia algo como um eletrocardiograma da televisão, servindo como incentivo a um forte engajamento da audiência.

Em linhas gerais, como sinalizam Proulx \& Shepatin (2012), o fenômeno Social TV decorre da convergência entre o sistema televisivo tradicional e as mídias sociais. Assim, podemos dizer que Social TVé uma modalidade de TV que se constitui a partir dos usos sociais, potencializados pelos recursos tecnológicos.

6 "A backchannel is a real-time online conversation using networked computers that takes place alongside live spoken remarks". <http://en.wikipedia.org/wiki/Backchannel (disambiguation)>.

7 Disponível em: <http://www.youtube.com/watch?v=Gl10JyKBtYw>. 
É um tipo de mídia descentralizada, que se constitui na recirculação de produtos convencionais.

É importante ressaltar, contudo, que há dois tipos de recirculação de produtos midiáticos: 1 ) simples recirculação, mantendo-se a formatação original e, no geral, seguindo um ordenamento estimulado pela mídia e 2) recirculação com modificação, na qual os produtos são adaptados aos interesses do usuário - uso social.

\section{Novas textualidades}

O contexto contemporâneo da comunicação é caracterizado pela cultura digital, que impacta decisivamente nos modos de pensar, produzir e consumir seus produtos (Montpetit, 2010; Giovagnoli, 2009; Jenkins, 2008).

Chega-se, a partir desse ponto, a uma ambiência discursiva que não é marcada apenas pelo texto ${ }^{8}$, mas que tem no contato interativo do leitor com modalidades textuais seu ponto principal. A característica basilar do relato interativo é que ele congrega uma diversidade de modalidades comunicacionais, como texto, imagens, vídeos etc. Escritura e leitura apartam-se de delimitações lineares. $O$ texto prevê ainda a participação do leitor ${ }^{9}$, que pode comentá-lo e reenviá-lo. A tecnologia possibilita ao texto uma existência cada vez mais marcada pela fluidez.

Para dar conta deste "texto em contato com outros textos", nos parece necessário explorar a noção de paratexto, proposta por Genette (1982; 1987). Tal conceito compreende o texto como estando em íntima ligação com uma estrutura que o envolve e contribui para que tome forma, produza sentido. Este texto, segundo Genette $(1987$, p.7), geralmente se apresenta reforçado por certo número de produções, verbais ou não.

O conceito de paratexto é, sem dúvida, determinante para se discutir a nova organização textual propiciada pela dimensão participativa e dialógica das formas de consumo contemporâneas, considerando-se, portanto, a ação do leitor neste cenário. A opção pelo conceito de paratexto justifica-se pela práxis

8 Para a presente discussão, compreende-se por texto todo e qualquer material midiático.

9 Essa ideia não é nova e pode ser localizada, por exemplo, no pensamento de Umberto Eco, em especial em "A obra aberta" (2001). O que temos é a passagem para níveis práticos de participação e/ ou interação com a obra, possível graças aos novos aparatos tecnológicos. 
que marca a criação dos novos textos, caracterizados por uma colagem, que fica a cargo do leitor/navegador (Dalmonte, 2009b).

O paratexto se constitui como um umbral, que põe em relação o que está dentro (no texto) e fora (o discurso sobre o texto). Para Genette (1987, p.08), a referência ao umbral não remete apenas a uma zona de transição entre uma textualidade e outra, mas, sobretudo, a uma zona de transação enquanto local privilegiado para estratégias, visando uma ação sobre o público, com o intuito de melhorar a acolhida do texto.

Os elementos que constituem o paratexto são oriundos de um conjunto marcado pela diversidade de práticas e discursos, que confluem para a formação do sentido da obra num contexto mais amplo. A noção de atualização envolvendo a obra resulta de uma movimentação social em torno de um produto que, não obstante traga as marcas que lhe foram agregadas no processo de feitura, está aberta a receber outras "inscrições", como resultado da apropriação social. Essa sobreposição de textualidades é a marca do que Genette (1982, p.08) chama de palimpsesto ou tipos de relações transtextuais.

Embora as reflexões acerca do paratexto estejam ligadas à literatura e à tradição do livro, as vias e modos do paratexto sofrem modificações constantes a partir das épocas, culturas, gêneros etc. Como ressalta Genette (1987, p.09), fica patente que na época midiática é multiplicada a produção de discursos que circundam uma obra, o que contribui sobremaneira para sua divulgação. A partir da premissa de que não existe texto sem paratexto, tal realidade abre uma série de questões quando se pensa nas potencialidades abertas pelas novas mídias. Merece relevo, a partir da nova fluidez textual dos ambientes digitais, a forma como os textos podem se desdobrar em blocos que se espalham nas redes sociais, de autorias diversas, mas conectados ao assunto em questão.

É interessante observar que os discursos sobrepostos sobre um texto "original" midiático, por mais distanciados que estejam de seu ponto de origem, ainda mantém um contato com o elemento desencadeador dessa narrativa diversificada. Entre opiniões favoráveis e contrárias, outras narrativas são estabelecidas a partir do texto original, conservando, contudo, a ligação com o protótipo, passando a compor um só texto, multilinear e multivocal. Esse espraiamento textual mantém, contudo, um princípio remissivo, pois a qualquer momento pode reconduzir ao elemento midiático "original".

Essa circulação/recirculação por meio das redes sociais confere ao texto original ares de sempre novo, sendo esta uma das características do paratexto: a constante atualização. Esse sentido de atualização confere/agrega ao produto "comentado/recirculado" uma permanência prolongada na cena midiática, em 
detrimento da uma passagem por vezes avassaladora, em termos da audiência, e ainda assim fugaz. Tal perspectiva já foi descrita por Anderson (2006), que sinaliza a transição de um mercado geral, massivo, para um amplamente segmentado, em nichos, que pode assegurar um consumo fragmentado e mesmo assim numericamente significativo.

\section{Mídia, discurso e interação}

Giorgio Agamben (2009, p. 38) apresenta importantes desdobramentos do conceito de dispositivo. Como ressalta, "o termo dispositivo nomeia aquilo em que e por meio do qual se realiza uma pura atividade de governo sem nenhum fundamento no ser. Por isso os dispositivos devem sempre implicar um processo de subjetivação, isto é, devem produzir o seu sujeito". Para a análise crítica, essa é uma importante perspectiva, pois permite vislumbrar a fragmentação do princípio motivador de ações sociais e o seu quase apagamento, a partir do processo de subjetivação.

A noção de dispositivo é fundamental para os estudos acerca da realidade midiática contemporânea, pois permite avaliar a natureza dos meios e de suas mensagens em interação com as novas dinâmicas de apropriação/consumo. Como pontua o autor, "chamarei literalmente de dispositivo qualquer coisa que tenha de algum modo a capacidade de capturar, orientar, determinar, interceptar, modelar, controlar e assegurar os gestos, as condutas, as opiniões e os discursos dos seres viventes" (Agamben, 2009, p.40).

Importa, a partir do conceito de dispositivo, pensar nas formas de passagem dos seres viventes, ou indivíduos, a sujeitos. Dos processos de subjetivação, resultam distintos usuários: de internet, de telefonia etc. Assim sendo, os dispositivos trazem aos indivíduos formas de usar - dos aparelhos aos afazeres culturais. Todo dispositivo é, então, disciplinar, entendendo-se por disciplinar as formas de estabelecer modos de usar e viver.

Os dispositivos atuam na conformação dos modos de interação com máquinas e artefatos culturais e, segundo Agamben (2009, p.44), são estabelecidos a partir da separação, ou captura, de aspectos inerentes aos indivíduos, como os desejos. A essa altura, o autor propõe trabalhar com os conceitos de sacralização e profanação.

A constituição de dispositivos é caracterizada, como num processo de sacralização, pela subtração de coisas, em geral, do uso comum e sua transferência a uma esfera privada, pertencente aos deuses. Assim, consagrar 
era, para o direito romano ${ }^{10}$, uma interdição que marcava a "a saída das coisas da esfera do direito humano". Por outro lado, "profanar significava, ao contrário, restituir ao livre uso dos homens" (Agamben, 2009, p.45).

O dispositivo que oficializa a separação entre aquilo de uso comum e o que é interditado é o sacrifício e todos os rituais daí decorrentes ${ }^{11}$. Para Agamben (2009, p.45), "a profanação é o contradispositivo que restitui ao uso comum aquilo que o sacrifício tinha separado e dividido".

Oideal da profanação, para Agamben (2007, p.66), é um tipo de negligência que não reconhece a separação ou a retirada de algo do plano corriqueiro das relações. Um tipo de profanação bastante ordinário é o jogo infantil:"as crianças, que brincam com qualquer bugiganga que lhes caia nas mãos, transformam em brinquedo também o que pertence à esfera da economia, da guerra, do direito e das outras atividades que estamos acostumados a considerar sérias" (Agamben, 2007, p.67).

O que importa é o resultado da profanação: a perda de sentido da separação e sua restituição ao uso (do que quer que seja) por parte dos sujeitos. Tal apontamento é determinante, pois na lógica dos dispositivos não há possibilidade de uso correto, tendo-se em vista o processo de subjetivação, que convoca sujeitos-usuários, com protocolos pré-estabelecidos.

Como sentencia Agamben (2007, p.75), “profanar não significa simplesmente abolir e cancelar as separações, mas aprender a fazer delas um uso novo, a brincar com elas". Assim sendo, um processo de profanação intenta assegurar formas de apropriação inusitadas e promover a reaproximação entre sujeitos e aquilo que lhes havia sido subtraído.

A partir dessas proposições, é possível estabelecer uma ótica que permita analisar as novas rotinas engendradas pelas formas de relação entre os produtos midiáticos e seus usuários. No contexto da interação entre plataformas distintas, como produtos televisivos, e as novas formas de consumo propostas pelos usuários de redes sociais, merece atenção os diversos modos de relacionamento dos leitores/navegadores com tais produtos.

A reverberação, ou recirculação, dos produtos midiáticos via redes sociais pode seguir distintas lógicas, ou funções: apenas a recirculação, ou agregando

10 Como pontua o autor: "direito e religião são, não apenas em Roma, estreitamente conexos". (Agamben, 2009, p.44).

11 Interessante reflexão sobre esse ponto é desenvolvido por Latour (2002) em "Reflexão sobre o culto moderno dos deuses fe(i)tiches". 
novos sentidos - opinião, humor etc. Os diversos fluxos estabelecidos pelos usuários podem indicar os seguintes itinerários, no contexto paratextual:

- prolongamento da obra, ou do tempo de circulação, em detrimento do tradicional tempo de exibição. Interessa, portanto, a passagem da temporalidade síncrona para a assíncrona;

- reforço da obra: interessa perceber o impacto da movimentação nas redes sociais na reconfiguração, ou fortalecimento, da audiência;

- desqualificação da obra, ou profanação: interessa observar os usos desviantes em relação ao que havia sido proposto pela instância de produção.

Assimsendo,osatos profanatóriosseconfiguramcomoelemento relevante para o entendimento dos processos de consumo midiático contemporâneos. A partir da interação entre redes sociais e produtos televisivos, no contexto da chamada Social TV, é possível verificar distintas formas de participação do indivíduo nos processos de circulação e recirculação de conteúdos midiáticos, observando-se: a) indicativos de reforço da programação tradicional e b) possibilidades de crítica e afastamento aos protocolos de leitura indicados pela instância de produção.

Se os produtos midiáticos contemporâneos são feitos para se "espalharem" em sucessivas esferas conversacionais, isso se deve tanto a questões técnicas quanto culturais, sendo a cultura da participação um importante elemento da cultura digital (Jenkins, 2008). Como ressaltam Jenkins, Ford e Green (2013, p.3), distintas lógicas estão presentes no ato de compartilhamento de conteúdos, tanto permitidos quanto contrários aos desejos da parte emissora. No contexto paratextual, pouco importa o imprimatur, mas as sucessivas movimentações engendradas entre produtores e consumidores.

Neste contexto em que os produtos midiáticos são pensados e produzidos segundo uma mudança de lógica da distribuição para a circulação, Jenkins, Ford e Green (2013, p.3) questionam as modalidades de fluxo que podem ser estabelecidas. As redes sociais estão sendo vistas como estrutura de apoio à divulgação da programação televisiva, por exemplo, propiciando o engajamento de novas audiências.

Contudo, é necessário traçar pelo menos dois caminhos distintos e um intermediário.

O primeiro caminho é o mais simples. Os produtos midiáticos estão sendo elaborados para o espalhamento em redes integradas a ferramentas que indicam ações como: curtir, compartilhar, comentar etc. Em questão de segundos, um elemento ganha o mundo. A essa modalidade está associado o conceito de mídia viral. Como ressaltam criticamente Jenkins, Ford e Green 
(2013, p.17), o conceito de vírus preserva o controle por parte dos criadores/ agentes midiáticos, bastando a criação de um viral para o sucesso de um produto. Nessa concepção, o viral é "irracional" e revela a susceptibilidade de um público que faz recircular, por intermédio de seus contatos em redes sociais, elementos subliminares alojados nas peças postas em circulação. Os vídeos que supostamente "vazam" servem de ilustração para essa modalidade ${ }^{12}$.

O segundo caminho expressa uma ação criativa por parte da audiência, sendo a apropriação de um elemento midiático, ao qual podem ser agregados outros sentidos, distintos daqueles propostos pela instância de produção. Como expressão de um ato profanatório, a audiência é reaproximada, de certa forma, do processo de produção e circulação de conteúdos. Esse processo é definido como Trollagem. Como exemplo, pode ser citada a campanha da Coca-Cola com latinhas personalizadas e o aplicativo para incluir nomes de amigos ou frases para o compartilhamento em redes sociais (FIG. 1). Embora aparentemente bem sucedida, a campanha também serviu de base para inúmeras trollagens (FIG. 2).

Um trecho de Chiquinha Gonzaga ${ }^{13}$, minissérie da Rede Globo, que foi ao ar ente janeiro e março de 1999, é o exemplo de Trollagem com um produto que foi amplamente difundido durante as manifestações de junho de 2013, contra o aumento das passagens. No trecho em questão, a personagem protesta contra o aumento das passagens do sistema de transporte público dos fins do século XIX, o bonde, numa referência ao episódio conhecido como a "Guerra do Vintém", ocorrido em $1879^{14}$.

Para Jenkins, Ford e Green (2013, p.27), toda recirculação, no contexto do espalhamento midiático é, de certa forma, um reordenamento do material posto em circulação, seja sampleando ou remixando aquilo que vai ser introduzido nas esferas conversacionais em diferentes plataformas. Todo esse processo marca um enfraquecimento da forma como se percebia a divisão entre as instâncias de produção e de consumo, bem como a rigidez de cada papel.

O terceiro caminho, ou via intermediária, marca uma apropriação "empresarial" das ações desenvolvidas pelos usuários das redes sociais. Esse movimento, em nosso entendimento, é uma tentativa de prender novamente um das pontas que se havia soltado no processo de produção e circulação de conteúdos midiáticos. Como exemplo, o Troll da Globo.com. Como apresentado

12 A novela Cheias de Charme (Rede Globo, abril - setembro de 2012) teve num "vazamento" de um vídeo amador o pivô central da narrativa. A audiência foi convocada para ver o material no Youtube. Disponível: <http://www.youtube.com/watch?v=Q xM0IKDaqQ $>$.

13 A minissérie retrata a vida de Francisca Edwiges Neves Gonzaga, a Chiquinha Gonzaga, importante maestrina e compositora brasileira do final do século XIX.

$14<$ http://memestroll.com.br/famosos/e-agora-globo/>. 
na definição "Sobre a Página"15: "O Troll é o lugar para se divertir com a programação do plim-plim de um jeito bem zoado. COMPARTILHE risadas e

FIG.1

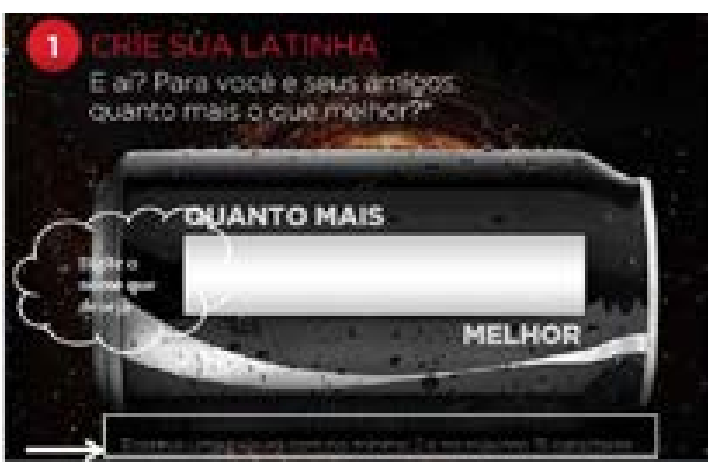

- Campanha da Coca-Cola Zero.
FIG.2

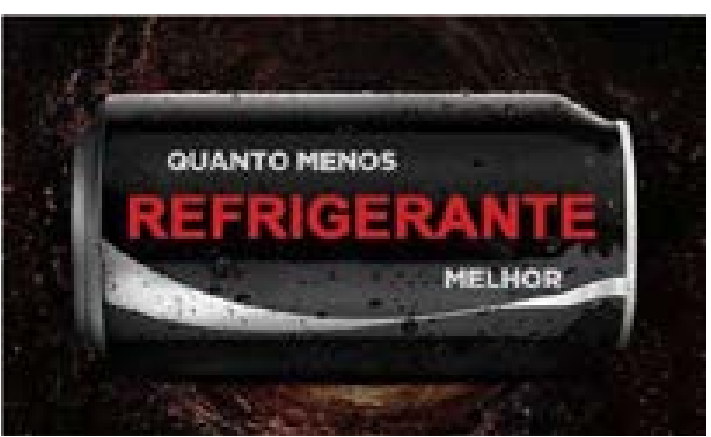

Trollagem.

CURTA à vontade. Este espaço é feito com o Morri de Sunga Branca".

O site Morri de Sunga Branca ${ }^{16}$ virou hit entre os usuários de redes sociais a partir de suas sátiras a celebridades e de suas versões hilárias sobre telenovelas, por exemplo. O Troll integra o GShow ${ }^{17}$, portal de entretenimento da Globo, lançado no dia 11 de janeiro de 2014. Dentre os objetivos do portal, está a ampliação da experiência televisiva, por meio do cruzamento da programação da emissora com os recursos da internet. Segundo matéria publicada no G1 $(G l o b o, 2014)^{18}$, a proposta é fazer "do GShow um espaço de integração entre o entretenimento da TV e a internet. O portal investe ainda na interatividade, com espaços abertos a comentários, enquetes, games, votações e compartilhamentos nas redes sociais".

Por meio da inclusão da equipe do Morri de Sunga Branca no Troll, percebese que o portal GShow se apresenta como espaço articulador das muitas vozes dispersas pelas redes sociais. Inclusive, adota-se o termo"curadoria" para a estratégia. "Essa 'curadoria' prevê a descoberta de novos talentos". (Globo, 2014). O sentido de curadoria adotado tende ao tradicional - seleção, mas como pontua Villi (2012,

15 Disponível: <http://gshow.globo.com/especial-blog/troll-tvg/1.html>.

$16<$ http://www.aimorridesungabranca.com/>.

$17<$ http://gshow.globo.com/>.

18 Matéria publicada no dia 11 de janeiro de 2014. Disponível: <http://g1.globo.com/pop-arte/ noticia/2014/01/globo-lanca-novo-portal-de-entretenimento-o-gshow.html>. 
p.615), o conceito é bem mais amplo, incluindo níveis de julgamento quanto a conteúdos gerados por usuários, por exemplo.

\section{Conclusões}

As estruturas conversacionais em rede têm possibilitado repensar o modelo comunicacional, tendo-se em vista a entrada em cena do leitor/ navegador via ferramentas interativas. O uso da palavra "entrar" ao invés de "incluir" é intencional e destaca a ação de um sujeito que passa a participar do processo desde as bordas e por essas bordas vai constituindo novos fluxos comunicacionais. Por outro lado, "inclusão" pode denotar a ação como sendo prioritariamente empreendida pela instância de produção - inclusão intencional e estratégica.

Dados da pesquisa "Social TV - Da TV para a Internet", realizada em 2013 pela eCGlobal Solutions, mostram que $86 \%$ dos brasileiros entrevistados gostam de comentar em redes sociais o que assistem na TV. A pesquisa evidencia um forte indicativo para o engajamento midiático via redes de conversação estabelecidos entre consumidores de programação televisiva.

Em relação à audiência dos produtos televisivos tradicionais, percebese que o impacto das novas estruturas de conversação possibilitadas pelos sites de redes sociais é positivo e pode contribuir para o aumento geral dos indicadores de consumo. Em detrimento da audiência síncrona, que põe numa mesma escala temporal a veiculação do produto e o consumo, surge uma nova perspectiva: a assíncrona. $O$ consumo assíncrono é caracterizado por distintos fluxos que vão sendo estabelecidos pela ação de uma audiência dispersa e que pode ir agregando novas marcas ao produto original.

Como característica paratextual, essa nova perspectiva de existência assíncrona pode evidenciar uma série de possibilidades: simples recirculação, recirculação opinativa, humorística ou uso desviante em relação ao sentido original. Para se entender as novas audiências e formas de consumo midiático, pouco importa os rumos dados pela recirculação dos conteúdos, pois em um dos extremos sempre estará o ponto de onde o elemento partiu. Assim, em uma esfera paratextual ampliada, a obra estará em constante atualização.

Fenômeno interessante ocorreu com a novela Amor à Vida ${ }^{19}$ e o descompasso entre algumas regiões brasileiras em decorrência do Horário de

19 Que esteve no ar entre maio de 2013 e janeiro de 2014. 
Verão ${ }^{20}$. O fato é que a transmissão acontecia primeiro nas regiões Sul e Sudeste. Com isso, usuários das redes sociais já iam discutindo elementos da trama numa esfera conversacional que, no geral, colocava em disputa os que já haviam visto e os que ainda iam ver os capítulos da trama. A prática dos spoilers, ou estraga prazeres, que "entregam" os segredos antes da hora, ao invés de diminuir o interesse, podem fortalecer a audiência.

Foi o que aconteceu, por exemplo, com o propalado "beijo gay" na referida telenovela. Enquanto na região Nordeste ainda havia dúvida se o beijo iria realmente acontecer no último capítulo ${ }^{21}$, o restante da audiência brasileira já comentava sobre ele nas redes sociais. Segundos após sua exibição já era possível ver inúmeros vídeos captados por celulares e outros dispositivos móveis circulando na rede. Por fim, pode-se dizer que a nova configuração da audiência desempenha um importante papel no contexto do consumo midiático contemporâneo. Ao invés de entendida como a meta final de um sistema de produção, a nova audiência mostra-se como parte do processo de circulação de conteúdos.

\section{Referências}

ANDERSON, Chris. A cauda longa. Do mercado de massa para o mercado de nicho. Rio de Janeiro: Elsevir, 2006.

AGAMBEN, Giorgio. O que é o contemporâneo? e outros ensaios. Chapecó, SC: Argos, 2009.

. Profanações. São Paulo: Boitempo, 2007.

DALMONTE, Edson F. Pensar o discurso no webjornalismo: temporalidade, paratexto e comunidades de experiência. Salvador: EDUFBA, 2009a. Disponível: < $\underline{\text { https:// }}$ repositorio.ufba.br/ri/bitstream/ufba/200/3/Pensar\%200\%20discurso\%20 no\%20webjornalismo.pdf>. Acesso em: 10 jan. 2014.

A esfera paratextual: o lugar do leitor-participante no webjornalismo. Galáxia, São Paulo, vol. 9, n. 18, 2009b, p. 113-124. Disponível: <http://revistas.pucsp.br/ index.php/galaxia/article/view/2645/1685>. Acesso em: 10 jan. 2014.

Presente: o tempo do jornalismo e seus desdobramentos. História, Franca, v. 29, n. 1, p. 328-344, 2010. Disponível em: <http://www.scielo.br/scielo.

20 A estratégia é adotada desde 2012 e no horário nobre tem a inversão da programação: a "novela das sete" vai ao ar depois do Jornal Nacional, para que o telejornal continue ao vivo em todo o território brasileiro.

21 Veiculado no dia 31 de janeiro. 
php?script=sci arttext\&pid=S0101-90742010000100019\&lng=pt\&nrm=iso >. Acesso em: 10 jan. 2014.

FRANCISCATO, Carlos Eduardo. A fabricação do presente: como o jornalismo reformulou a experiência do tempo nas sociedades ocidentais. São Cristóvão: Editora UFS, 2005.

GENETTE, Gérard. Seuils. Paris: Éditions du Seuil, 1987.

Palimpsestes: la littérature au second degré. Paris: Éditions du Seuil, 1982.

GIOVAGNOLI, Max. Cross-media: Le nuove narrazione. Milano: Apogeo, 2009.

GLOBO lança novo portal de entretenimento, o GShow. G1, 11 de jan. 2014. Disponível: $<$ http://g1.globo.com/pop-arte/noticia/2014/01/globo-lanca-novo-portal-deentretenimento-o-gshow.html>. Acesso em: 10 jan. 2014.

HARBOE, Gunnar. Introduction to Social TV. In: Mobile TV Customizing Content and Experience. Springer, London, 2010.

JENKINS, Henry. Cultura da convergência. Editora Aleph, 2008.

JENKINS, Henry; FORD, Sam; GREEN, Joshua. Spreadable media. Creating value and meaning in a networked culture. New York University Press, 2013.

LATOUR, Bruno. Reflexão sobre o culto moderno dos deuses fe(i)tiches. São Paulo: Edusc, 2002.

MONTPETIT, Marie-José. Your content, your networks, your devices: Social networks meet your TV Experience. ACM Comput. Entertainment Environments archive, Volume 7, Issue 3, Article 34, September, 2009.

; KLYM, Natalie; BLAIN, Emmanuel. The Future of Mobile TV: When Mobile TV Meets the Internet and Social Networking. In: Mobile TV Customizing Content and Experience. Springer, London, 2010.

ORTIZ, Júnia. Configurações da experiência televisiva: o consumo social na Internet. Dissertação (Mestrado em Comunicação) Programa de Pós-Graduação em Comunicação. FACOM/UFBA, 2013.

PROULX, Mike; SHEPATIN, Stacey. Social TV. How marketers can reach and engage audiences by connecting television to the web, social media, and mobile. John Wiley \& sons, 2012.

SCHATZ, Raimund, e outros. "What are you viewing?" Explore the pervasive Social TV experience. In: Mobile TV Customizing Content and Experience. Springer, London, 2010. 
VILLI, Mikko. Social curation in audience communities: UDC (user-distributed content) in the networked media ecosystem. Participations. Journal of Audience \& Reception Studies. Volume 9, número 2, 2012. Disponível: <http://participations. org/Volume\%209/Issue\%202/33\%20Villi.pdf>. Acesso em: 10 jan 2014

Recebido em: 13 janeiro 2015

Aceito em: 26 fevereiro 2015

Endereço do autor:

Edson Fernando Dalmonte <edsondalmonte@gmail.com>

Programa de Pós-Graduação em Comunicação e Culturas

Contemporâneas, Faculdade de Comunicação

Endereço: Av. Barão de Geremoabo, s/no - Campus de Ondina

Cidade: Salvador - BA - CEP: 40170-115

Fone: (71) 3235.4858 